\title{
Sclerosis and blisters: An uncommon association revealing a new case of bullous morphea
}

\author{
Soraya Aouali', Saida Sefraoui', Kaoutar Sof ${ }^{1}$, Siham Dikhaye ${ }^{1,2}$, Nada Zizi ${ }^{1,2}$
}

${ }^{1}$ Department of Dermatology, Mohamed 6 University Hospital of Oujda, Morocco, ${ }^{2}$ Laboratory of Epidemiology, Clinical Research and Public Health, Faculty of Medicine and Pharmacy, Mohamed the first university of Oujda, Oujda, Morocco

Corresponding author: Soraya Aouali, MD, E-mail: soraya.aouali@gmail.com

\begin{abstract}
Bullous morphea is a rare variant of localized scleroderma (morphea) characterized by subepidermal bullae developed over sclerotic plaques. The pathogenesis of bullae formation has been the subject of several debates, which arrived at the conclusion of a multifactorial mechanism. We report the case of a 67-year-old patient with bullous morphea of the trunk and thighs, who showed a good response to PUVA therapy combined with topical steroids. Our case report supports the efficiency of PUVA therapy associated with topical steroids as a safe regimen compared to other therapeutic approaches.
\end{abstract}

Key words: Bullous Morphea; Sclerosis; Bullae

\section{INTRODUCTION}

Bullous morphea is a rare variant of localized scleroderma (morphea) that presents a diversified semiology, with tense bullae overlying plaque-type, linear, or deep sclerotic lesions. Histologically, it is associated with epidermal atrophy, subepidermal blistering, and prominent thick bundles of hyalinized collagen that destroy the adnexal structures. The pathogenesis of bullae formation has been the subject of several debates, which arrived at the conclusion of a multifactorial mechanism. Numerous treatments have been proposed, but the therapeutic strategy is still poorly codified.

We report the case of a 67 -year-old patient with bullous morphea of the trunk and thighs.

\section{CASE REPORT}

A 67-year-old female with a history of diabetes and high blood pressure presented herself at our dermatology department with pruritic lesions on the abdomen evolving one month prior to the visit.
A physical examination revealed multiple sclerotic and dyschromic plaques localized symmetrically on the lower side of the breasts, abdomen, and thigh roots. The plaques were bordered by tense and serous bullae, arranged in an annular pattern, with generalized scaling, and covering $30 \%$ of the body surface (Fig. 1).

A skin biopsy was performed on a bullous lesion and histopathology revealed sclerodermiform dermal fibrosis with subepidermal blistering housing punctuate serum spots, red blood cells, and mature lymphocytes, as well as telangiectasias of the papillary dermis (Fig. 2). An autoimmunity assessment was negative.

The patient received 27 PUVA therapy sessions combined with daily topical steroids, and reported total disappearance of the bullous lesions and noticeable softening of the sclerotic areas, with regression of the sclerotic skin surface to $4 \%$ at the end of the treatment.

\section{DISCUSSION}

Morphea may appear on different aspects, and the bullous form is its rarest variant. Its first case was

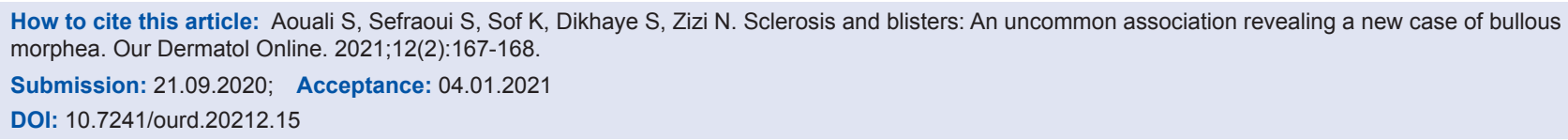




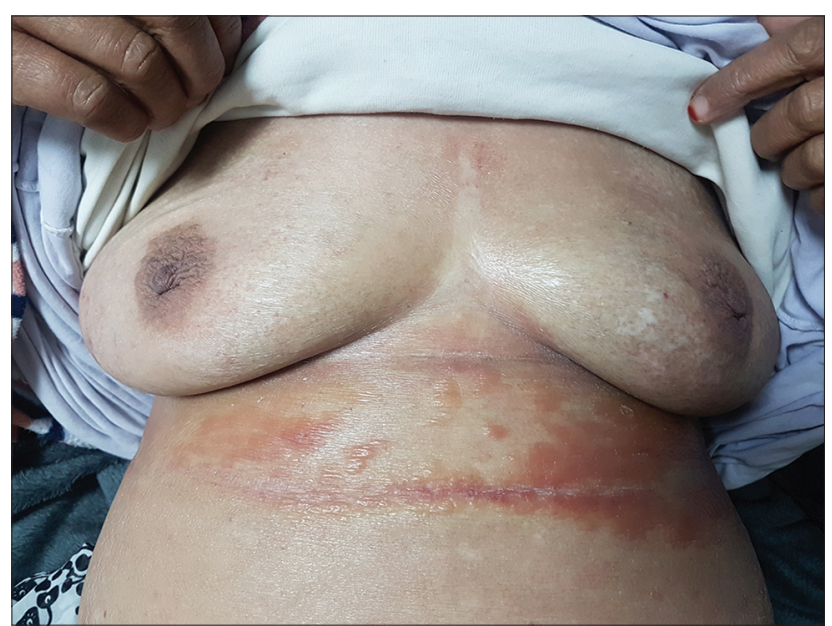

Figure 1: Clinical photo showing sclerotic plaques bordered by tense bullae.

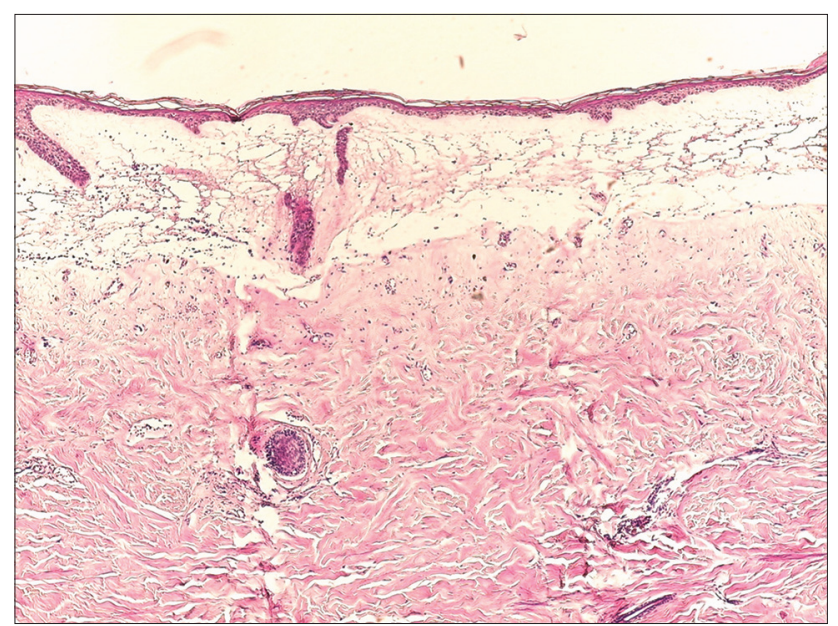

Figure 2: Histopathological image showing sclerodermiform dermal fibrosis with subepidermal blistering.

described by Morrow in 1896 [1]. Since then, it has been described in several anecdotal reports and small series.

An eight-year retrospective American study identified 53 cases of scleroderma, with only four cases of bullous morphea $(7.5 \%)$ [2].

A more recent study, including 137 cases of localized scleroderma over a period of eleven years, showed a lower frequency of the bullous form, which was observed in two cases (1.4\%) [3].

The pathogenesis of bullae formation has been the subject of several debates. Indeed, the blistering mechanism may be multifactorial, resulting from subepidermal edema induced by lymphangiectasias secondary to cutaneous sclerosis, excessive skin trauma, or friction to an area of low resistance [4].

The therapeutic approach is similar to the treatment regimens for non-bullous morphea and is based on topical treatments (topical steroids, vitamin D analogs) or phototherapy in first intention and the use of synthetic antimalarials, immunosuppressants, colchicine, or systemic retinoids in severe cases [5].

\section{CONCLUSION}

Bullous morphea is a rare pathology and its diagnosis is based on clinical and histological findings. The pathophysiology of bullae formation is multifactorial and its management is essentially based on topical steroids, phototherapy, and immunosuppressants in resistant forms. Our case report supports the efficiency of PUVA therapy combined with topical steroids in bullous morphea.

\section{Consent}

The examination of the patient was conducted according to the principles of the Declaration of Helsinki.

The authors certify that they have obtained all appropriate patient consent forms, in which the patients gave their consent for images and other clinical information to be included in the journal. The patients understand that their names and initials will not be published and due effort will be made to conceal their identity, but that anonymity cannot be guaranteed.

\section{REFERENCES}

1. Daoud MS, Su WPD, Leiferman KM, Perniciaro DaC. A case of symmetrical morphea attended with the formation of bullae and extensive ulceration. J Cutan Genito-Urin. 1896;14:419-27.

2. Rencic A, Goyal S, Mofid M, Wigley F, Nousari HC. Bullous lesions in scleroderma. Int J Dermatol. 2002;41:335-9.

3. Venturi M, Pinna AL, Pilloni L, Atzori L, Ferreli C, Rongioletti F. Bullous morphoea: a retrospective study. Clin Exp Dermatol. 2017;42:532-5.

4. Fernandez-Flores A, Gatica-Torres M, Tinoco-Fragoso F, García-Hidalgo L, Monroy E, Saeb-Lima M. Three cases of bullous morphea: histopathologic findings with implications regarding pathogenesis. J Cutan Pathol. 2015;42:144-9.

5. Sánchez-Pérez S, Escandell-González I. Hospital Clínico Universitario de Valencia, Valencia, España. Bullous morphea: description of a new case and discussion of etiologic and pathogenic factors in bulla formation. Actas Dermosifiliogr. 2017;108:75-6.

Copyright by Soraya Aouali, et al. This is an open-access article distributed under the terms of the Creative Commons Attribution License, which permits unrestricted use, distribution, and reproduction in any medium, provided the original author and source are credited. Source of Support: Nil, Conflict of Interest: None declared. 